\title{
Biometals as Potential Predictors of the Neurodegenerative Decline in Alzheimer's Disease.
}

\author{
Liseth K. Lavado ${ }^{1}$, Michelle H. Zhang ${ }^{2}$, Karan Patel ${ }^{3}$, Sohim Khan ${ }^{4}$, Urvish K. Patel ${ }^{5}$
}

1. Nursing, Rutgers School of Nursing, Newark, USA 2. Psychological \& Brain Sciences and Biology, Johns Hopkins University, Baltimore, USA 3. Neuroscience, Johns Hopkins University, Baltimore, USA 4. Public Health, Icahn School of Medicine at Mount Sinai, New York, USA 5. Neurology and Public Health, Icahn School of Medicine at Mount Sinai, New York, USA

Corresponding author: Urvish K. Patel, dr.urvish.patel@gmail.com

\begin{abstract}
Alzheimer's Disease (AD) is a debilitating neurodegenerative disease that is diagnosed by gradual memory loss and certain cognitive impairments involving attention, reasoning, and language. Most of the research on Alzheimer's disease focuses on the correlation of its neuropathological changes in the neurofibrillary tangles caused by hyper-phosphorylated tau protein and $\beta$-amyloid plaques with respect to cognitive impairment. Its pathology, however, remains incompletely understood. Currently, research has demonstrated that environmental factors such as biometals play a crucial role in exacerbating $\mathrm{AD}$ progression. The present review examines the role of metals in $\mathrm{AD}$ progression and how metal dyshomeostasis attributes to $\mathrm{AD}$ pathogenesis.

It was found that certain metals possess both beneficial and harmful properties in terms of $\mathrm{AD}$ progression. Depending upon the concentration of the metal of interest, copper, zinc, iron, and selenium have general beneficial properties. However, when present in excess, they can lead to oxidative stress and hyperphosphorylation of tau protein, amongst other harmful effects, while calcium and magnesium were seen to have beneficial effects by regulating biometal uptake.
\end{abstract}

In this review, we have provided evidential studies that focus on the involvement of certain metals in antioxidant pathways leading to the formation of reactive species indicative of neurodegeneration.

Categories: Neurology, Environmental Health, Epidemiology/Public Health

Keywords: alzheimer's disease, mild cognitive impairment, amyloid- $\mathbf{X}$, biometals, copper, calcium, iron, neurodegenerative disease, zinc

Received 08/26/2019

Review began 08/26/2019

Review ended 08/28/2019

Published 09/05/2019

๑) Copyright 2019

Lavado et al. This is an open access article distributed under the terms of the Creative Commons Attribution License CC-BY 3.0., which permits unrestricted use, distribution, and reproduction in any medium, provided the original author and source are credited.

\section{Introduction And Background}

Alzheimer's disease $(\mathrm{AD})$ is an irreversible brain disorder that affects over 6 million individuals. Ten percent of the current population over the age of sixty-five sufferers from $\mathrm{AD}$, and this percentage doubles for every five years past this age. As a result, half the population over the age of eighty suffers from AD. Although research funding for Alzheimer's is higher than it has ever been, there is still no effective therapeutic agent to this disease. $\mathrm{AD}$ originates in the medial temporal lobe and follows the perforant path from the entorhinal cortex to the dentate gyrus, before moving to the frontal lobe toward the posterior cingulate cortex. It is a progressive disease and has an intermediate form known as Mild Cognitive Impairment (MCI) before it is clinically diagnosed as Alzheimer's Disease [1].

In the most common form of MCI, patients express concern over the fact that they are beginning to lose memory, performing significantly worse on memory tasks compared to age-matched healthy controls. Some patients with MCI go on to develop full-blown $\mathrm{AD}$, with demonstrable psychological, behavioral and cognitive deficits. In terms of the symptoms corresponding to $\mathrm{AD}$, patients face psychological deficits including hallucinations or paranoia. The most prominent behavioral and cognitive deficits in patients with $\mathrm{AD}$ are emotional agitation and severe mental and cognitive declines well beyond those of age-matched controls [1].

The primary neuropathological signatures of Alzheimer's Disease (AD) are amyloid plaques and intraneuronal neurofibrillary tangles, which are formed from the aggregation of insoluble hyperphosphorylated tau protein and amyloid- $\mathbf{X}(\mathrm{A} \beta)$. $A \beta$ is a proteolytic fragment of a precursor of a transmembrane protein, while tau is a microtubule-associated protein. Over recent years, it has been shown that, in $\mathrm{AD}$ pathogenesis, $\mathrm{A} \beta$ causes the conversion of wildtype tau to a hyperphosphorylated-version. This results in a positive feedback loop where hyper-phosphorylated tau increases the neurotoxicity of $A \beta$, which in turn causes an increase in hyper-phosphorylated tau [2]. 
Recent research on $\mathrm{AD}$ has shed light on the possible effects of environmental factors which can contribute to the progression of $\mathrm{AD}$. Specifically, research has shown that certain biometals are able to favor the maturation of $A \beta$ protein aggregation, leading to further toxicity [3]. These biometals include copper, zinc, magnesium, and calcium, among others. These distinct metals are important for a variety of reasons, from the spatial co-localization of copper, zinc, and iron, to the regulating effects of calcium and magnesium, to the cross-linked effects of copper, selenium, and iron in AD mediation [3-5].

Many of these metals can be seen to be beneficial in moderate, physiological concentrations/amounts, but when observed to be in excess, they can prove harmful and exacerbatory to AD pathology. Majority of the benefits that these biometals provide are seen in their ability to either support cellular antioxidants or act as antioxidants themselves $[3,6,7]$. It is important to identify these beneficial effects of biometals to better understand the necessity of homeostasis, as a deficiency may result in impaired cellular processes and increased oxidative stress [3]. Aside from these benefits, though, certain metals are detrimental in excess concentrations, contributing to $\mathrm{A} \beta$ secretion and hyper-phosphorylation of tau; for example, in high concentrations, zinc and copper will promote these processes, thus increasing oxidative stress. Often, these processes are paired with metal reductions and the formation of toxic free radicals. It is widely known that $\mathrm{AD}$ pathology is greatly related to the effects of $\mathrm{A} \beta$ aggregation--neuroinflammation--and those of hyperphosphorylated tau--neurofibrillary tangles. Hence, it is in the best interests of AD patients, to determine amounts of these metals in the body and establish ways of preventing dyshomeostasis.

This review paper examines current research on the function of biometals on the onset and progression of AD. Particularly, we examine and discusses the role of copper, zinc, magnesium, calcium, iron and selenium in $\mathrm{AD}$ pathology and provide information on how changes in metal concentrations can exacerbate disease progression in elderly individuals. We aimed to present a detailed overview of both the harmful effects of excess high concentrations of certain biometals and the beneficial mediating roles of other metals in regulated amounts.

\section{Review \\ Metals of interest}

The biometals that have been implicated in $\mathrm{AD}$ progression are copper, zinc, magnesium, calcium, iron and selenium, primarily because of the role these metals play in regulating the neuronal synaptic activity. In particular, research has shown that $\mathrm{Cu} 2+, \mathrm{Zn} 2+$, and $\mathrm{Fe} 2+$ are found in the core and rims of senile plaques in $\mathrm{AD}$ patients and co-localize with $\mathrm{A} \beta[4]$. Therefore, altering the baseline levels of these metals can interfere with homeostasis within synapses and stimulate the production of free radicals, which in turn can trigger neurodegeneration [3]. Particularly, copper, iron, zinc, magnesium and calcium play a role in inducing $A \beta$ protein aggregation and oxidative stress [7]. For instance, iron acts as a catalyst for $A \beta$ protein aggregation by forming reactive oxygen species (ROS) [3], whereas the other metals are involved in other pathways. Although not much research is available on selenium, limited research has shown that selenium can also induce free radical formation and oxidative stress [3].

\section{Role of metals in AD}

Copper and Zinc

Copper is an essential micronutrient and a redox-active metal that has been associated in $\mathrm{AD}$ pathogenesis. It is needed by Superoxidant Dismutase 1 (SOD1), which is a vital cellular antioxidant [7]. It has also been found that the interaction of $\mathrm{Cu} 2+$ and $\mathrm{A} \beta$ forms hydrogen peroxide $\left(\mathrm{H}_{2} \mathrm{O}_{2}\right)$, as a byproduct, which further contributes to the formation of hydroxyl radicals related to $\mathrm{AD}$ pathogenesis [6]. While zinc provides structural support to SOD1, an excess concentration of $\mathrm{Zn2}+$ contributes to the hyper-phosphorylation of tau, a cytosolic protein involved in microtubule assembly and stability [6,7]. An overabundance of copper and zinc can also be detrimental by promoting the production of reactive oxygen species (ROS), which can further damage proteins, DNA, and lipids [7]. For instance, in mice model studies, it was found that molecules designed to chelate $\mathrm{Zn} 2+$ and $\mathrm{Cu} 2+$ from $\mathrm{A} \beta$ aggregates increased $\mathrm{A} \beta$ solubilization, subsequently decreasing $A \beta$ deposits [6]. Additionally, research has found that super-stoichiometric levels of these metals result in insoluble and amorphous aggregates, which aggregate into oligomeric precursors rather than organized fibrils [6]. This eventually leads to the formation of tau-paired helical filaments (PHF), which ultimately gather to form neurofibrillary tangles (NFT).

Additionally, zinc and copper are implicated in AD through complications associated with metallothioneins. Metallothioneins belong to a family of ubiquitous proteins and are capable of binding metals and serving as antioxidants [6]. In particular, neuronal metallothionein 3 (MT3) is involved in the transport and homeostasis of $\mathrm{Zn} 2+$ and $\mathrm{Cu} 2+$, which helps to reduce $\mathrm{A} \beta$ aggregation and increase soluble amyloid precursor proteins (sAPP $\alpha$ ) [6]. sAPP $\alpha$ helps to promote neuronal survival and neurite outgrowth [6]. MT3, in particular, interacts with $\mathrm{A} \beta$ to abolish $\mathrm{Cu} 2+$ mediated aggregation [6]. As a result, a defect in the MT3 pathway can lead to the increased aggregation that is seen in $\mathrm{AD}$ patients.

Magnesium and Calcium 
Magnesium and calcium play a role in $\mathrm{AD}$ through their relationship with $\mathrm{A} \beta \mathrm{PP}$ and presenilins. Additionally, zinc and copper are implicated in the pathway of presenilins. Presenilins are evolutionarily conserved proteins, which serve as the $\gamma$-secretase multi-protein complex catalytic subunit and act as novel regulators of cellular zinc and copper uptake [5]. The $\gamma$ - secretase multi-protein complex is responsible for cleaving A $\beta P P$; however, mutations resulting in overexpression of presenilin, particularly in the genes encoding presenilins PS1 and PS2, are crucial indicators of the majority of AD cases [5]. Mutations in presenilins result in the downregulation of $\mathrm{Ca} 2+$ channels and $\mathrm{Ca} 2+$ dependent mitochondrial transport proteins that strengthen the relationship between presenilin and $\mathrm{Ca} 2+$ homeostasis. This downregulation is evident in familial forms of $\mathrm{AD}$ [6]. Research has suggested that both $\mathrm{Ca} 2+$ and $\mathrm{Mg} 2+$ stabilize $\gamma$-secretase and enhance its activity [6], which contributes to a decrease in $A \beta$.

Iron

Research has shown that $A \beta$ aggregation in the brain leads to inflammation and oxidative stress resulting in increased iron deposition [6]. In a positive feedback cycle, increased iron deposition causes more oxidative stress, which then contributes to early $A \beta$ deposition [8]. As a result, $A \beta$ has been found to alter redoxinactive ferric iron $(\mathrm{Fe} 3+)$, which is generally present as a reserve form of iron (ferrihydrite), to redox-active ferrous iron $(\mathrm{Fe} 2+)$. Redox-inactive ferrous iron acts as the catalyst of Fenton reactions that produce toxic free radicals, which subsequently drive neuroinflammation [9]. For instance, it has been shown that elderly individuals who exhibit mild cognitive impairment (MCI) exhibit an increased iron deposition in the cortex and cerebellum [4]. Additional research has shown that there is a relationship between A $\beta P P$ and iron homeostasis. Particularly, AßPP contains a non-canonical iron response element (IRE) in the 5' uncoded region of mRNA, which allows the translation of mRNA to be placed directly under iron regulatory proteins (IRPs), specifically IRP1 [10]. This suggests that an increase in intracellular levels of iron leads to increased amounts of AßPP [10]. As a result, an excess of iron contributes to $A \beta$ production and leads to annular protofibrils, which slows the formation of ordered cross- $\beta$ fibrils, leading to more disordered and toxic aggregates [6]. Additionally, A $\beta$ PP plays a crucial role in iron homeostasis as it contains a sequence within the protein that allows it to interact with ferroportin and improve iron export [11].

Another key to maintaining proper iron levels is hepcidin, a regulatory hormone that is synthesized in the liver and allows for a decreased release of iron [12]. Hepcidin regulates iron via ferroportin, an iron export protein located on the cell surface of macrophages, enterocytes, and hepatocytes, and leads to its internalization and degradation in order to prevent cellular export of iron. The interaction between A $\beta P P$ with ferroportin promotes iron export and its ferroxidase activity [6]. Additionally, just as zinc promotes hyper-phosphorylation in the tau protein, Fe3+ induces aggregation by binding to tau; likewise, a reduction in Fe2+ could reverse the aggregation of tau [6]. This suggests that iron dyshomeostasis could contribute to $\mathrm{AD}$ neuroinflammatory pathology because an excess of iron can lead to oxidative stress and perpetuate tau hyper-phosphorylation [6].

Research has also suggested that iron expression of iron metabolism-associated proteins such as divalent metal transporter 1 (DMT1)--a proton-coupled metal ion transport--and ferroportin 1 (FPN1), which is responsible for iron absorption in the intestines due to its role of exporter of iron, could affect the iron load in the brain [13].

Selenium

The function of selenium is twofold. First, varying the concentrations of selenium can help mediate AD. For instance, high levels of selenium increase the formation of free radicals due to its ability to oxidize endogenous sulfhydryl groups [3]. However, selenium also acts as an antioxidant. The effects of selenium as an antioxidant are particularly seen through a pathway that involves glutathione peroxidase (GSH-Px). A deficiency in selenium can, therefore, interfere with GSH-Px and lead to oxidative stress [3].

\section{Findings from prior studies}

Effects of Copper and Zinc in mediating $A D$

In terms of the role of presenilins in mediating $\mathrm{AD}$, a study on Drosophilia melangogaster showed that Presenilin knockdown was related to an elevated susceptibility to paraquat, a potent inducer of superoxide [5]. The inability of Presenilin to regulate copper and zinc uptake leads to an increase in the concentrations of these metals and contributes to metal dyshomeostasis, which further leads to the oxidative stress seen in $\mathrm{AD}$ patients [5].

\section{Effects of Calcium in mediating $A D$}

Hyper-phosphorylation of tau proteins, one of the pathological dysfunctions of $\mathrm{AD}$, results when microtubule formation is inhibited, which leads to neurofibrillary tangles and instability of the cytoskeletal system, causing double helix fibers. These double helix fibers are the main structures in AD and eventually elicit neuronal death [14]. Calcium/calmodulin-dependent protein kinase IV (CAMK4) is a serine/threonine 
kinase that phosphorylates transcription factors that control memory consolidation. The principal role of CAMK4 is to phosphorylate microtubule-associated protein 2 and tau protein. CAMK4 is activated by calmodulin (CALM) binding to Ca2+ when intracellular Ca2+ levels increase. This favors calcium-calmodulin complex formation, which then activates calcium/calmodulin-dependent protein kinase kinase 1 (CAMKK1) through phosphorylation. CAMKK1 subsequently activates CAMK4 by phosphorylation [14].

Genistein (GS), a 4',5,73 hydroxy isoflavone compound from soybean and other plant species, is a promising compound that has shown neuroprotective effects in treating and preventing $\mathrm{AD}$ by reducing the deposition of $A \beta$, resisting toxicity and inflammatory damage, regulating calcium levels, and reducing apoptosis in the hippocampus [15]. Furthermore, GS was seen to improve learning and memory in AD model rats [14].

In a study done to evaluate the neuroprotective role of GS, researchers utilized the Morris water maze test to measure the memory consolidation ability of 80 female Sprague Dawley rats aged 10 months. The study tracked the escape latency-time taken to find and climb onto the platform-of four groups of rats: the sham group, the $\mathrm{AD}$ group, the GS group, and estradiol valerate (EV) group as a positive control group. It revealed that the AD rats' escape latency increased, meaning that they took more time to find and climb unto the platform, and the number of times they were able to successfully cross the original platform location after removal of the platform was significantly reduced in comparison to the sham group. When compared to the $\mathrm{AD}$ group though, the GS and EV groups had significantly reduced escape latencies and increased number of original platform crossings, indicating that GS improved learning and memory in AD model rats [14]. Moreover, it was also found that the hippocampal neuronal cells of the GS group were closely packed and uniform in color compared to those of AD group, which were disordered, and some even died as characterized by cell shrinkage. On the other hand, the sham group cells were strongly packed, displayed intact colored nuclei and hyperchromatic nucleoli [14]. The EV group hippocampal neurons increased in number and were rarely stained, in contrast to the AD group, whose cells exhibited dark red staining after lysis. These results indicate that GS exhibits a neuroprotective effect. Further, p-CAMK4, CALM and CAMKK1 levels were highest in the hippocampus in the AD group compared to the sham, GS and EV groups [14], indicating that GS can reduce these levels through calcium regulation, playing an important role in the mediation of AD.

Iron association in neuroinflammatory $A D$ pathology

In a study performed to examine iron-associated neuroinflammatory AD pathology, researchers imaged 5 control human hippocampal and $5 \mathrm{AD}$ brain specimens using 7T MRI at ultra-high resolution. The aim was to quantify the location of iron with respect to microglia and A $\beta$. Microglia activated through the Fenton reaction are responsible for imitating an inflammatory response in $\mathrm{AD}$ patients. It was hypothesized that iron accumulation would be found within activated microglia instead of $A \beta$, which would indicate the inflammatory components of $\mathrm{AD}$ [15]. The results of this study identified many minor MR hypointensities within the subiculum of the hippocampus. This was best explained by a combination of activated microglia $(p=0.025)$ and microscopic iron, as opposed to the involvement of tau and amyloid, which were less prevalent [15]. These results indicate that the presence of iron, specifically $\mathrm{Fe} 2+$, influences microglia activation and subsequently causes an inflammatory reaction that leads to neurodegeneration.

Likewise, in another study, researchers assessed whether there were differences in the serum level of hepcidin and other related factors (serum iron, serum ferritin, \% saturation and total iron-binding capacity (TIBC)) as potential markers for $\mathrm{AD}$ and MCI. The study sample consisted of $52 \mathrm{AD}$ patients (pure $\mathrm{AD}$ was confirmed in 19 patients via autopsy), 9 MCI patients, and 24 control patients. Frozen serum samples of the subjects were collected and analyzed using enzyme-linked immunosorbent assay (ELISA) to measure hepcidin serum levels, ferritin, and TIBC. It was found that the iron-related serum measurements were higher in $\mathrm{AD}$ patients in comparison to controls and that the group differences in serum ferritin were statistically significant $(p=0.025)$ [12]. The study found high serum ferritin levels to be observed in both MCI patients and patients with early-stage AD-stages in which there are relatively low serum iron levels [12]. This suggests that inflammation could be the cause of the observed increase in serum ferritin as ferritin is made up of two subunits characterized by their molecular weight, $\mathrm{H}$ and $\mathrm{L}$, with $\mathrm{H}$ subunits increasing during inflammation and oxidative stress [12]. This increase of $\mathrm{H}$ subunits can disrupt the $\mathrm{H} / \mathrm{L}$ ratio and lead to $\mathrm{H}$-subunit derived ferroxidase activity and higher levels of unliganded iron, which have the potential for cellular damage [12].

Cross-linked effects of Copper, Selenium and Iron in mediating $A D$

The previously presented idea that there is an increase in serum iron levels in AD patients was confirmed by another study conducted on $32 \mathrm{AD}$ patients comparing the concentration of copper, selenium, and iron in elderly $\mathrm{AD}$ patients to the serum concentration of healthy control subjects [3,12]. The researchers found that patients with a Clinical Dementia Rating (CDR) level of CDR-2 and CDR-3 exhibited high levels of iron ( $\mathrm{p}=$ $(0.009,0.017)$ and copper $(p=0.013,0.0010)$, with CDR-3 patients exhibiting lower selenium levels than the healthy controls $(\mathrm{p}=0.008)[3]$. They concluded that the increase in copper levels was due to ceruloplasmin enzyme expression. Ceruloplasmin enzyme binds to copper and decreases its unrestricted concentration and so increased expression of this enzyme would account for the increased copper levels. Additionally, the high 
levels of copper was found to be directly proportional to the peroxide levels, which increases the concentrations of free radicals and subsequently increase oxidative stress in patients [3]. Lastly, the researchers mention that the accumulation of high levels of iron in brain regions such as the hippocampus, basal ganglia, cerebral cortex, and neurofibrillary tangles, or around senile plaques could lead to neurodegeneration [3], which supports the small MR hypointensities found within the subiculum of the hippocampus of the aforementioned study [15]. Table 1 summarizes the effect of biometals in AD.

\begin{tabular}{|c|c|c|}
\hline Metal & $\begin{array}{l}\text { Iron-Binding } \\
\text { Protein }\end{array}$ & Effect \\
\hline $\mathrm{Cu}^{2+}$ & $\begin{array}{l}\text { Amyloid- } \beta \text { (AB) } \\
\text { peptide }\end{array}$ & $\begin{array}{l}\text { Harmful: Interaction between } \mathrm{Cu}^{2+} \text { and } A \beta \text { is correlated with a metal reduction from } \mathrm{Cu}(\mathrm{II})->\mathrm{Cu}(\mathrm{l}) \text { along with the } \\
\text { formation of } \mathrm{H}_{2} \mathrm{O}_{2} \text {, leading to hydroxyl free radicals [6]. } \mathrm{A} \beta \text { promotes oxidative stress in the presence of redox } \\
\text { metals, copper, and iron [6]. }\end{array}$ \\
\hline $\mathrm{Cu}^{2+}$ & $\begin{array}{l}\text { Metallothionein } \\
3 \text { (MT3) }\end{array}$ & $\begin{array}{l}\text { Harmful: Defects in MT3 pathway lead to increased aggregation of A } \beta \text { as MT3 is involved with the homeostasis of } \\
\mathrm{Zn}^{2+} \text { and } \mathrm{Cu}^{2+} \text { by increasing soluble amyloid precursor proteins (sAPPa) [6]. }\end{array}$ \\
\hline $\mathrm{Zn}^{2+}$ & $\begin{array}{l}\text { Amyloid- } \beta(A \beta) \\
\text { peptide }\end{array}$ & $\begin{array}{l}\text { Beneficial [at low levels]: Competes with iron/copper to bind to } A \beta \text { to prevent } \mathrm{Cu}-\mathrm{A} \beta \text { induced formation of } \mathrm{H}_{2} \mathrm{O}_{2} \text { and } \\
\text { toxic free radicals [6]. Harmful [in excess]: Oxidants releasing excess zinc can trigger neuronal death that may be } \\
\text { related to the toxic effect of } A \beta[6] \text { Studies found that high concentrations of zinc-binding to } A \beta \text { force } A \beta \text { to } \\
\text { participate over a wide range of } p H[16] \text {, and preserve the highly ordered conformation of } A \beta \text {, producing toxic, } \\
\text { fibrillar } A \beta \text { aggregates [6]. }\end{array}$ \\
\hline $\mathrm{Zn}^{2+}$ & Tau Protein & $\begin{array}{l}\text { Harmful [in excess]: The pathological concentration of } \mathrm{Zn}^{2+} \text { dramatically accelerated the abnormal aggregation of } \\
\text { full-length human Tau [in Sh-SY5Y cells] [17], in addition to enhancing Tau aggregation in neuronal cells and Tau } \\
\text { aggregation-induced apoptosis and toxicity. Contributes to hyperphosphorylation of tau [6], and lead to the } \\
\text { formation of tau-paired helical filaments (PHF) that gather into neurofibrillary tangles (NFT). }\end{array}$ \\
\hline $\mathrm{Mg}^{2+}$ & $\begin{array}{l}\text { Amyloid- } \beta \\
\text { Protein } \\
\text { Precursor } \\
\text { (AßPP) }\end{array}$ & $\begin{array}{l}\text { Beneficial: Decreased intracellular } \mathrm{Ma}^{2+} \text { levels impair cell viability; magnesium modulates } \mathrm{A} \beta \mathrm{PP} \text { processing as } \\
\text { follows [18]. High } \mathrm{Mg}^{2+} \text { promotes non-amyloidogenic A } \beta P P \text { cleavage through a-secretase while demoting } \\
\text { amyloidogenic processing by } \beta \text {-secretase [18], which is typically associated with the formation of amyloid plaque } \\
\text { [19]. Lowering } \mathrm{Mg}^{2+} \text { concentration sees the opposite, detrimental effects [18]. }\end{array}$ \\
\hline $\mathrm{Ca}^{2+}$ & $\begin{array}{l}\text { AßPP \& } \\
\text { Presenilins }\end{array}$ & $\begin{array}{l}\text { Beneficial: } \mathrm{Both} \mathrm{Ca}^{2+} \text { and } \mathrm{Mg}^{2+} \text { stabilize } \mathrm{\gamma} \text {-secretase (which cleaves } \mathrm{A} \beta \mathrm{PP} \text { ), enhancing its activity and decreasing } \\
\mathrm{A} \beta \text { secretion }[6] . \text { Mutations in presenilins downregulate } \mathrm{Ca}^{2+} \text { channels and } \mathrm{Ca}^{2+} \text { dependent mitochondrial transport } \\
\text { proteins, which is seen in familial forms of } \mathrm{AD}[6]\end{array}$ \\
\hline $\mathrm{Fe}^{2+}$ & $\begin{array}{l}\text { Amyloid- } \beta \\
\text { peptide }\end{array}$ & $\begin{array}{l}\text { Harmful: Increased iron deposition leads to oxidative stress, contributing to early A } \mathrm{A} \text { deposition [8]. Excess of iron } \\
\text { leads to annular protofibrils, slowing formation of ordered cross- } \beta \text { fibrils and resulting in disordered, toxic } \\
\text { aggregates [6]. In short, excess iron is linked to neuron loss in AD brain [20], iron enhances the toxicity of A } \mathrm{A} \text { in } \\
\text { cultured neural cells [21]. Iron in reduced } \mathrm{Fe}^{2+} \text { state accelerates cell damage through toxic hydroxyl radical } \\
\text { formation catalyzation [10]. }\end{array}$ \\
\hline $\mathrm{Fe}^{2+}$ & Tau protein & $\begin{array}{l}\text { Harmful: } \mathrm{Fe}^{3+} \text { induces aggregation through tau-binding Reduction of } \mathrm{Fe}^{2+} \text { can reverse this aggregation Iron } \\
\text { dyshomeostasis can contribute to } \mathrm{AD} \text { neuroinflammation by causing oxidative stress and tau hyperphosphorylation } \\
\text { [similar to zinc] [6]. }\end{array}$ \\
\hline $\mathrm{Fe}^{2+}$ & $\begin{array}{l}\text { Divalent metal } \\
\text { transport } 1 \\
\text { (DMT1) and } \\
\text { Ferroportion } 1 \\
\text { (FPN1) }\end{array}$ & Harmful: Expression of these iron metabolism-associated proteins could affect iron load in the brain negatively [13]. \\
\hline Selenium & $\begin{array}{l}\text { sulfhydryl } \\
\text { groups }\end{array}$ & $\begin{array}{l}\text { Harmful [in excess]: In high concentrations, Se can oxidize endogenous sulfhydryl groups, increasing free radical } \\
\text { formation [22]. Beneficial [in moderation]: Acts as an antioxidant component Deficiency results in glutathione } \\
\text { peroxidase (GSH-Px) impairment, resulting in oxidative stress [23]. }\end{array}$ \\
\hline & AI & IS \\
\hline
\end{tabular}

Table 2 mentions brief information from previous studies showing the evidence of ion-binding proteins in the progression of $\mathrm{AD}$. 


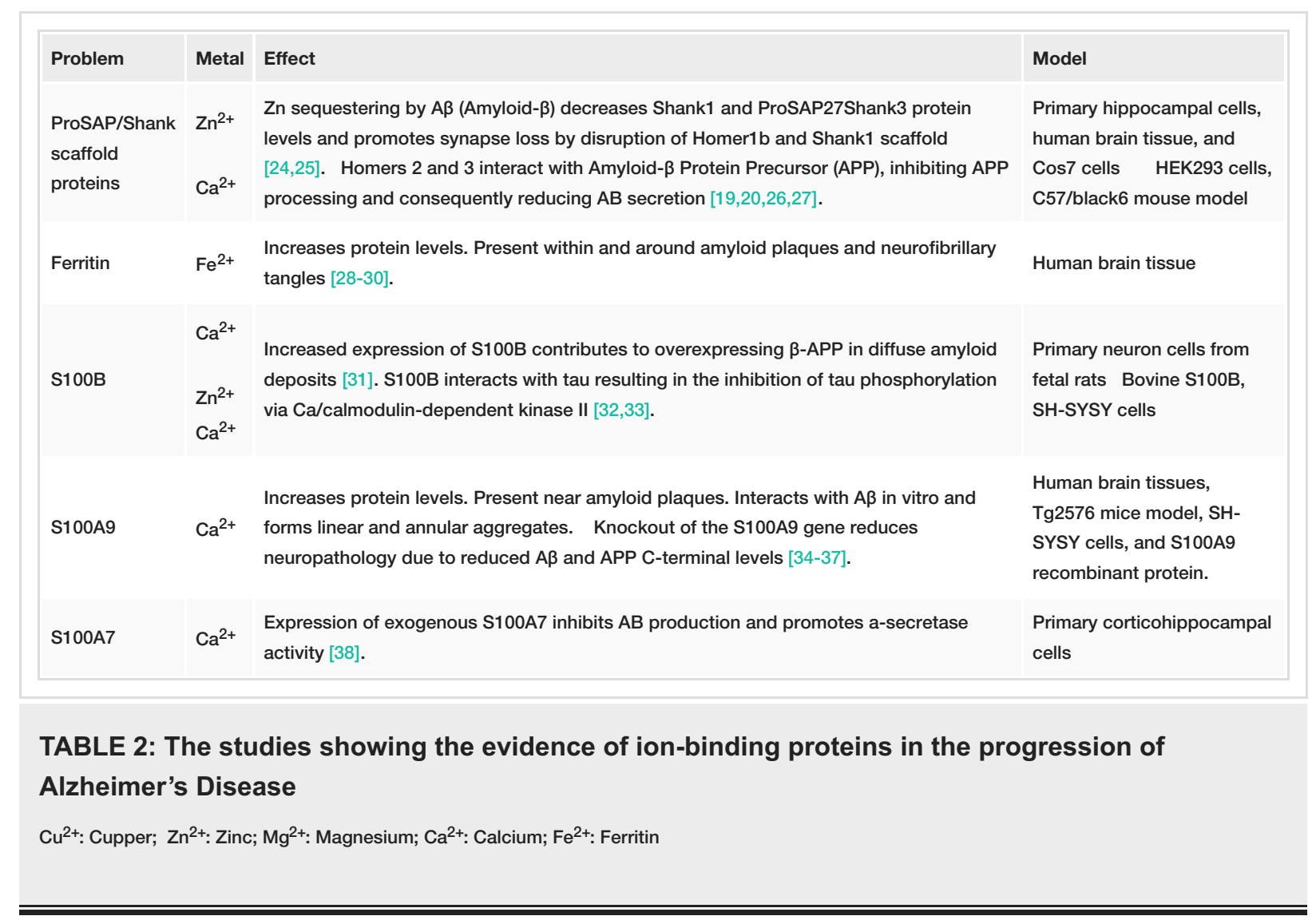

\section{Conclusions}

The latest research on $\mathrm{AD}$ suggests that the progression of $\mathrm{AD}$ is influenced by the presence of biometals. That is why it is important to study how the dyshomeostasis and interaction of certain metals can induce AD as there is presently no cure for AD. Recent studies indicate that certain metals, especially in high concentrations, can induce the formation of $A \beta$ aggregates and reactive oxygen species leading to oxidative stress. The data in the research indicates that the presence of excess iron in particular influences the progression of $\mathrm{AD}$ as it undergoes the Fenton reaction and forms free radicals. Likewise, other biometals such as magnesium and calcium interfere with the cleavage of A $\beta P P$ and presenilin function, which further causes the formation of $A \beta$ aggregates and oxidative stress. Similarly, copper has been shown to mediate the progression of $\mathrm{AD}$ because of the role it plays in the presenilin pathway. The current research provides evidence on the effects of metals in $\mathrm{AD}$ and suggests that treatment options for $\mathrm{AD}$ should focus on balancing the dyshomeostasis of the metals involved.

\section{Additional Information}

\section{Disclosures}

Conflicts of interest: In compliance with the ICMJE uniform disclosure form, all authors declare the following: Payment/services info: All authors have declared that no financial support was received from any organization for the submitted work. Financial relationships: All authors have declared that they have no financial relationships at present or within the previous three years with any organizations that might have an interest in the submitted work. Other relationships: All authors have declared that there are no other relationships or activities that could appear to have influenced the submitted work.

\section{Acknowledgements}

Nidhi Patel, BS, Drexel University College of Medicine, Philadelphia, for her effort to review the literature and proofread the article.

\section{References}

1. Petersen RC: Early diagnosis of Alzheimer's disease: Is MCI too late? . Curr Alzheimer Res. 2009, 6:324-330. 10.2174/156720509788929237

2. Doig AJ: Positive feedback loops in Alzheimer's disease: The Alzheimer's feedback hypothesis . J Alzheimers Dis. 2018, 66:25-36. 10.3233/JAD-180583 
3. Vaz FNC, Fermino BL, Haskel MVL, et al.: The relationship between copper, iron, and selenium levels and Alzheimer disease. Biol Trace Elem Res. 2018, 181:185-191. 10.1007/s12011-017-1042-y

4. Smith MA, Zhu X, Tabaton M, et al.: Increased iron and free radical generation in preclinical Alzheimer disease and mild cognitive impairment.. J Alzheimers Dis. 2010, 19:363-372. 10.3233/JAD-2010-1239

5. Southon A, Greenough MA, Ganio G, Bush AI, Burke R, Camakaris J: Presenilin promotes dietary copper uptake. PLOS ONE. 2013, 8:e62811. 10.1371/journal.pone.0062811

6. Jomova K, Vondrakova D, Lawson M, Valko M: Metals, oxidative stress and neurodegenerative disorders . Mol Cell Biochem. 2010, 345:91-104.

7. Avramovich-Tirosh Y, Amit T, Bar-Am O, Zheng H, Fridkin M, Youdim MBH: Therapeutic targets and potential of the novel brain- permeable multifunctional iron chelator-monoamine oxidase inhibitor drug, M-30, for the treatment of Alzheimer's disease. J Neurochem. 2007, 100:490-502.

8. Greenough MA, Camakaris J, Bush AI: Metal dyshomeostasis and oxidative stress in Alzheimer's disease . Neurochem Int. 2013, 62:540-555. 10.1016/j.neuint.2012.08.014

9. Everett J, Céspedes E, Shelford LR, et al.: Ferrous iron formation following the co-aggregation of ferric iron and the Alzheimer's disease peptide $\beta$-amyloid (1-42). J R Soc Interface. 2014, 11:20140165. 10.1098/rsif.2014.0165

10. Rogers JT, Bush AI, Cho H-H, et al.: Iron and the translation of the amyloid precursor protein (APP) and ferritin mRNAs: riboregulation against neural oxidative damage in Alzheimer's disease. Biochem Soc Trans. 2008, 36:1282-1287. 10.1042/BST0361282

11. Cho H-H, Cahill CM, Vanderburg CR, et al.: Selective translational control of the Alzheimer amyloid precursor protein transcript by iron regulatory protein-1. J Biol Chem. 2010, 285:31217-31232. 10.1074/jbc.M110.149161

12. Sternberg Z, Hu Z, Sternberg D, et al.: Serum hepcidin levels, iron dyshomeostasis and cognitive loss in Alzheimer's disease. Aging Dis. 2017, 8:215-227. 10.14336/AD.2016.0811

13. Dong X-H, Gao W-J, Kong W-N, et al.: Neuroprotective effect of the active components of three Chinese herbs on brain iron load in a mouse model of Alzheimer's disease. Exp Ther Med. 2015, 9:1319-1327. 10.14336/AD.2016.0811

14. Ye S, Wang T-T, Cai B, et al.: Genistein protects hippocampal neurons against injury by regulating calcium/calmodulin dependent protein kinase IV protein levels in Alzheimer's disease model rats. Neural Regen Res. 2017, 12:1479-1484. 10.4103/1673-5374.215260

15. Zeineh MM, Chen Y, Kitzler HH, Hammond R, Vogel H, Rutt BK: Activated iron-containing microglia in the human hippocampus identified by magnetic resonance imaging in Alzheimer disease. Neurobiol Aging. 2015, 36:2483-2500. 10.1016/j.neurobiolaging.2015.05.022

16. Cuajungco MP, Fagét KY: Zinc takes the center stage: its paradoxical role in Alzheimer's disease . Brain Res Brain Res Rev. 2003, 41:44-56. 10.1016/S0165-0173(02)00219-9

17. Hu J-Y, Zhang D-L, Liu X-L, et al.: Pathological concentration of zinc dramatically accelerates abnormal aggregation of full-length human Tau and thereby significantly increases Tau toxicity in neuronal cells. Biochim Biophys Acta BBA - Mol Basis Dis. 2017, 1863:414-427. 10.1016/j.bbadis.2016.11.022

18. Yu J, Sun M, Chen Z, et al.: Magnesium modulates amyloid-beta protein precursor trafficking and processing. J Alzheimers Dis. 2010, 20:1091-1106. 10.3233/JAD-2010-091444

19. Tyler SJ, Dawbarn D, Wilcock GK, Allen SJ: $\alpha$ - and $\beta$-secretase: profound changes in Alzheimer's disease . Biochem Biophys Res Commun. 2002, 299:373-376. 10.1016/S0006-291X(02)02635-9

20. Smith CD, Carney JM, Starke-Reed PE, et al.: Excess brain protein oxidation and enzyme dysfunction in normal aging and in Alzheimer disease. Proc Natl Acad Sci U S A. 1991, 88:10540-10543. 10.1073/pnas.88.23.10540

21. Schubert D, Chevion M: The role of iron in beta amyloid toxicity. Biochem Biophys Res Commun. 1995, 216:702-707. 10.1006/bbrc.1995.2678

22. Nogueira CW, Meotti FC, Curte E, Pilissão C, Zeni G, Rocha JBT: Investigations into the potential neurotoxicity induced by diselenides in mice and rats. Toxicology. 2003, 183:29-37. 10.1016/S0300483X(02)00423-7

23. Santos JR, Gois AM, Mendonça DMF, Freire MAM: Nutritional status, oxidative stress and dementia: the role of selenium in Alzheimer's disease. Front Aging Neurosci. 2014, 6:206. 10.3389/fnagi.2014.00206

24. Pham E, Crews L, Ubhi K, et al.: Progressive accumulation of amyloid- $\beta$ oligomers in Alzheimer's disease and in amyloid precursor protein transgenic mice is accompanied by selective alterations in synaptic scaffold proteins. FEBS J. 2010, 277:3051-3067. 10.1111/j.1742-4658.2010.07719.x

25. Grabrucker AM, Schmeisser MJ, Udvardi PT, et al.: Amyloid beta protein-induced zinc sequestration leads to synaptic loss via dysregulation of the ProSAP2/Shank3 scaffold. Mol Neurodegener. 2011, 6:65. 10.1186/1750-1326-6-65

26. Kyratzi E, Efthimiopoulos S: Calcium regulates the interaction of amyloid precursor protein with Homer3 protein. Neurobiol Aging. 2014, 35:2053-2063. 10.1016/j.neurobiolaging.2014.03.019

27. Parisiadou L, Bethani I, Michaki V, Krousti K, Rapti G, Efthimiopoulos S: Homer2 and Homer3 interact with amyloid precursor protein and inhibit A $\beta$ production. Neurobiol Dis. 2008, 30:353-364. 10.1016/j.nbd.2008.02.004

28. Jellinger K, Paulus W, Grundke-Iqbal I, Riederer P, Youdim MBH: Brain iron and ferritin in Parkinson's and Alzheimer's diseases. J Neural Transm - Park Dis Dement Sect. 1990, 2:327-340. 10.1007/BF02252926

29. Connor JR, Menzies SL, Martin SMS, Mufson EJ: A histochemical study of iron, transferrin, and ferritin in Alzheimer's diseased brains. J Neurosci Res. 1992, 31:75-83. 10.1002/jnr.490310111

30. Quintana C, Bellefqih S, Laval JY, et al.: Study of the localization of iron, ferritin, and hemosiderin in Alzheimer's disease hippocampus by analytical microscopy at the subcellular level. J Struct Biol. 2006, 153:42-54. 10.1016/j.jsb.2005.11.001

31. Li Y, Wang J, Sheng JG, et al.: S100 $\beta$ increases levels of $\beta$-Amyloid precursor protein and its encoding mRNA in rat neuronal cultures. J Neurochem. 1998, 71:1421-1428. 10.1046/j.1471-4159.1998.71041421.x

32. Yu WH, Fraser PE: S100ß interaction with Tau is promoted by zinc and inhibited by hyperphosphorylation in Alzheimer's Disease. J Neurosci. 2001, 21:2240-2246. 10.1523/JNEUROSCI.21-07-02240.2001 


\section{Cureus}

33. Baudier J, Cole RD: Interactions between the microtubule-associated tau proteins and S100b regulate tau phosphorylation by the Ca2+/calmodulin-dependent protein kinase II. J Biol Chem. 1988, 263:5876-5883.

34. Shepherd CE, Goyette J, Utter V, et al.: Inflammatory S100A9 and S100A12 proteins in Alzheimer's disease . Neurobiol Aging. 2006, 27:1554-1563. 10.1016/j.neurobiolaging.2005.09.033

35. Wang C, Klechikov AG, Gharibyan AL, et al.: The role of pro-inflammatory S100A9 in Alzheimer's disease amyloid-neuroinflammatory cascade. Acta Neuropathol (Berl). 2014, 127:507-522. 10.1007/s00401-0131208-4

36. Chang K-A, Kim HJ, Suh Y-H: The role of S100a9 in the pathogenesis of Alzheimer's disease: The therapeutic effects of S100a9 knockdown or knockout. Neurodegener Dis. 2012, 10:27-29. 10.1159/000333781

37. Zhang C, Liu Y, Gilthorpe J, Maarel JRC van der: MRP14 (S100A9) protein interacts with Alzheimer betaamyloid peptide and induces its fibrillization. PLOS ONE. 2012, 7 :e32953. 10.1371/journal.pone.0032953

38. Qin W, Ho L, Wang J, Peskind E, Pasinetti GM: S100A7, a novel Alzheimer's disease biomarker with nonamyloidogenic $\alpha$-Secretase activity acts via selective promotion of ADAM-10. PLOS ONE. 2009, 4:e4183. 10.1371/journal.pone.0004183 